OPEN ACCESS

Edited by: Andrea Genre

Università degli Studi di Torino, Italy

Reviewed by:

Stéphane Compant

Austrian Institute of Technology,

Austria

Rodica Pena,

University of Göttingen, Germany

${ }^{*}$ Correspondence:

Kelly D. Craven

kdcraven@noble.org

Specialty section:

This article was submitted to

Plant Microbe Interactions,

a section of the journal

Frontiers in Plant Science

Received: 02 August 2017 Accepted: 19 December 2017

Published: 09 January 2018

Citation:

Ray P, Guo Y, Kolape J and Craven KD (2018) Non-targeted Colonization by the Endomycorrhizal

Fungus, Serendipita vermifera,

in Three Weeds Typically

Co-occurring with Switchgrass.

Front. Plant Sci. 8:2236.

doi: $10.3389 / f p / s .2017 .02236$

\section{Non-targeted Colonization by the Endomycorrhizal Fungus, Serendipita vermifera, in Three Weeds Typically Co-occurring with Switchgrass}

\author{
Prasun Ray, Yingqing Guo, Jaydeep Kolape and Kelly D. Craven* \\ Noble Research Institute, LLC, Ardmore, OK, United States
}

Serendipita vermifera (=Sebacina vermifera; isolate MAFF305830) is a mycorrhizal fungus originally isolated from the roots of an Australian orchid that we have previously shown to be beneficial in enhancing biomass yield and drought tolerance in switchgrass, an important bioenergy crop for cellulosic ethanol production in the United States. However, almost nothing is known about how this root-associated fungus proliferates and grows through the soil matrix. Such information is critical to evaluate the possibility of non-target effects, such as unintended spread to weedy plants growing near a colonized switchgrass plant in a field environment. A microcosm experiment was conducted to study movement of vegetative mycelia of S. vermifera between intentionally inoculated switchgrass (Panicum virgatum L.) and nearby weeds. We constructed size-exclusion microcosms to test three different common weeds, large crabgrass (Digitaria sanguinalis L.), Texas panicum (Panicum texanum L.), and Broadleaf signalgrass (Brachiaria platyphylla L.), all species that typically co-occur in Southern Oklahoma and potentially compete with switchgrass. We report that such colonization of non-target plants by $S$. vermifera can indeed occur, seemingly via co-mingled root systems. As a consequence of colonization, significant enhancement of growth was noted in signalgrass, while a mild increase (albeit not significant) was evident in crabgrass. Migration of the fungus seems unlikely in root-free bulk soil, as we failed to see transmission when the roots were kept separate. This research is the first documentation of non-targeted colonization of this unique root symbiotic fungus and highlights the need for such assessments prior to deployment of biological organisms in the field.

Keywords: grass endophyte, microcosm, mycorrhiza, Panicum virgatum, Rhizobox, Sebacina

\section{INTRODUCTION}

The Serendipitaceae (formerly Sebacinales Group B) belong to a taxonomically, ecologically and physiologically diverse group of fungi in the Basidiomycota (kingdom Fungi). While historically recognized as orchid mycorrhizae, recent ITS based phylogenetic studies have demonstrated both their pandemic distribution and the broad spectrum of mycorrhizal types they form (Warcup, 1988; Suarez et al., 2008; Oberwinkler et al., 2013). Indeed, ecological studies using PCR-based detection 
methods have found Serendipitaceae in field specimens of bryophytes (mosses), pteridophytes (ferns) and all families of herbaceous angiosperms (flowering plants) from temperate, subtropical and tropical regions. These natural host plants include, among others, liverworts, wheat, maize and Arabidopsis thaliana, a genetic model plant traditionally viewed as non-mycorrhizal (Warcup, 1988; DeMars and Boerner, 1996; Selosse et al., 2002). Serendipita vermifera exemplifies this phenotype, and though it was originally isolated from an Australian orchid (Warcup, 1988), we have successfully established beneficial interactions between this fungal species and many different experimental hosts, including the model plant Arabidopsis (Ray and Craven, 2016). Considering their proven beneficial effects on switchgrass growth (Ghimire and Craven, 2011; Ray et al., 2015) and their apparent ubiquity (Weiss et al., 2011), Serendipitaceae fungi should be considered as a previously hidden, but amenable and effective microbial tool for enhancing plant productivity and stress tolerance.

Switchgrass (Panicum virgatum L.) has been identified by the United States Department of Energy as an important biofeedstock for cellulosic ethanol production (McLaughlin and Kszos, 2005). A large part of the rationale behind its selection relates to an astonishingly deep root system that enhances nutrient and water uptake, as well as stabilizes the soil matrix and fixes carbon, both ecological services that promote its utility on marginal landscapes (Ma et al., 2000). Although productive and competitive with minimal inputs once established, weed competition can impede establishment success and resulting productivity (Schmer et al., 2006; Mitchell et al., 2008) of switchgrass. Unfortunately, this extensive root system is also an Achilles heel in the first year of cultivation (establishment), as most productivity goes to root production and little is allocated to the shoots. Co-occurring annual broadleaf weeds are common in the establishment of switchgrass, and if populations are dense, establishment can be reduced (Renz et al., 2009).

As weed competition is indeed the most common cause of establishment failure in switchgrass, and Serendipitaceae fungi appear to have an extraordinarily broad host range, the possibility for un-intended colonization of weedy species in the vicinity of inoculated switchgrass plants exists. Therefore, we sought to document the incidence of non-targeted colonization of commonly co-occurring weeds when growing alongside a switchgrass colonized with $S$. vermifera. Toward this end, we conducted two unique greenhouse based microcosm studies to investigate the ability of $S$. vermifera to colonize non-targeted crops via movement through a root-free bulk soil or via an interconnected network of roots likely present in a majority of natural and agricultural plant communities. We used switchgrass as our intended target of inoculation and three different competing weeds, large crabgrass (Digitaria sanguinalis), Texas panicum (Panicum texanum) and broadleaf signalgrass (Brachiaria platyphylla), as "bait" for testing nontarget effects. Each of these weeds was chosen as they are known to be typically present in the Southern Oklahoma region (Miller et al., 1975; Blount et al., 2003) and potentially compete with switchgrass (Kering et al., 2013). This research would not only inform efficient weed management strategies when
Serendipitaceae fungi are utilized, but also weighs in on the decision to deploy non-native microbes in a broader sense.

\section{MATERIALS AND METHODS}

\section{Plant Material}

Seeds of large crabgrass (Digitaria sanguinalis), Texas panicum (Panicum texanum), broadleaf signalgrass (Brachiaria platyphylla) and switchgrass (Panicum virgatum L.), cultivar Alamo were procured from The Noble Research Institute, LLC. All the seeds were briefly surface sterilized following the protocol modified after Xi et al. (2009). Briefly, seeds were washed with $50 \%$ Clorox $^{\circledR}$ (8.25\% sodium hypochlorite, Clorox, Oakland, CA, United States) containing 0.1\% TWEEN ${ }^{\circledR} 20$ (Amresco, Solon, OH, United States) for $30 \mathrm{~min}$. After five washes with sterile water, seeds were soaked in sterile water and kept in $4^{\circ} \mathrm{C}$ overnight. Subsequently, seeds were treated one additional time with $50 \%$ Clorox $^{\circledR}$ for 30 min, washed with sterile water for five times and air dried on sterile filter paper. Surface sterilized seeds were sown in sterile Metro-Mix ${ }^{\circledR} 360$ (Sungro Horticulture, Agawam, MA, United States) and maintained in the green house for germination under standard conditions (temperature range, $26-29^{\circ} \mathrm{C}$ ) with $50 \%$ relative humidity under a $16: 8 \mathrm{~h}$ photoperiod. Four week-old uniform size seedlings were used for all subsequent experiments.

\section{Preparation of Inoculum Using Bentonite Clay as a Carrier}

The S. vermifera strain MAFF305830 used in this study was obtained from the National Institute of Agro-biological Sciences, Tsukuba, Japan. Clay particle based inoculum of $S$. vermifera was prepared as described in Ray et al. (2015). The clay particles were thoroughly sieved using mesh size $10(2 \mathrm{~mm})$ to get a uniform particle size. One-liter media bottles were filled with $400 \mathrm{ml}$ of clay particles by volume and $150 \mathrm{ml}$ of Modified Melin Norkan's (MMN) (Marx, 1969) media pH 7. The clay particles and MMN media were mixed homogeneously by shaking, and then sterilized by autoclaving. Each bottle was inoculated with $50 \mathrm{ml}$ of a 4-week-old $S$. vermifera liquid culture prepared in 250-ml Erlenmeyer flasks. An equivalent amount of MMN broth was added to a control set of bottles used as mock inoculum in this study. Both the mock and the inoculated bottles were incubated in a slanted, stationary position at $24^{\circ} \mathrm{C}$ for 8 weeks. The bottles were agitated once per week for uniform distribution of the inoculum.

\section{Preparation of the Microcosm Assemblies}

To investigate controlled, non-targeted colonization, we created two unique microcosm assemblies developed at Noble Research Institute, LLC as illustrated in Figures 1, 2. As the plant compartments are externally connected, we designated the first microcosm (Figure 1) assembly as an "exocosm." Conversely, as all plants in the second microcosm assembly (Figure 2) were placed inside a single pot, around a central compartment, we 

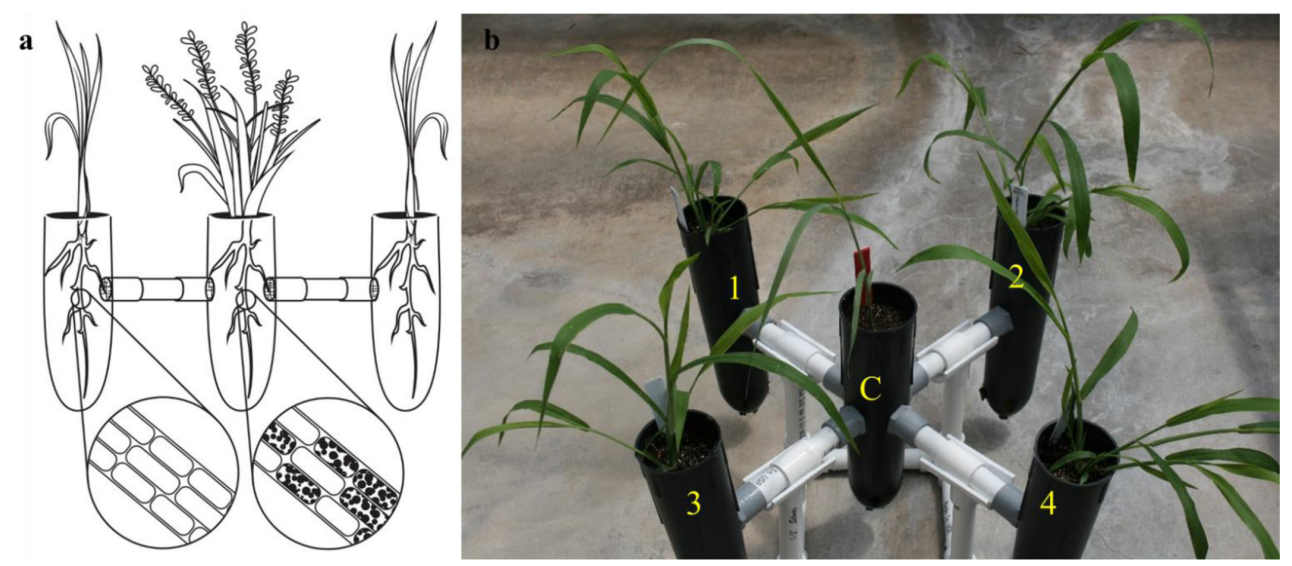

FIGURE 1 | The exocosm assembly to investigate the movement of S. vermifera between switchgrass and competing weeds mediated by vegetative mycelia. (a) Illustration of an exocosm assembly. The colonization of individual root cells at the end of the study by $S$. vermifera are represented by black dots (enlarged) in the illustration. (b) Five single-cell root trainers were connected by $16 \mathrm{~cm}$ long PVC pipes. The openings of the four connector pipes were covered with fine nylon mesh from either side to exclude roots but allow the movement of the finer fungal mycelia. Switchgrass in the center (C) was colonized with S. vermifera (MAFF305830). Weeds in the four corners (1 4) were not colonized.

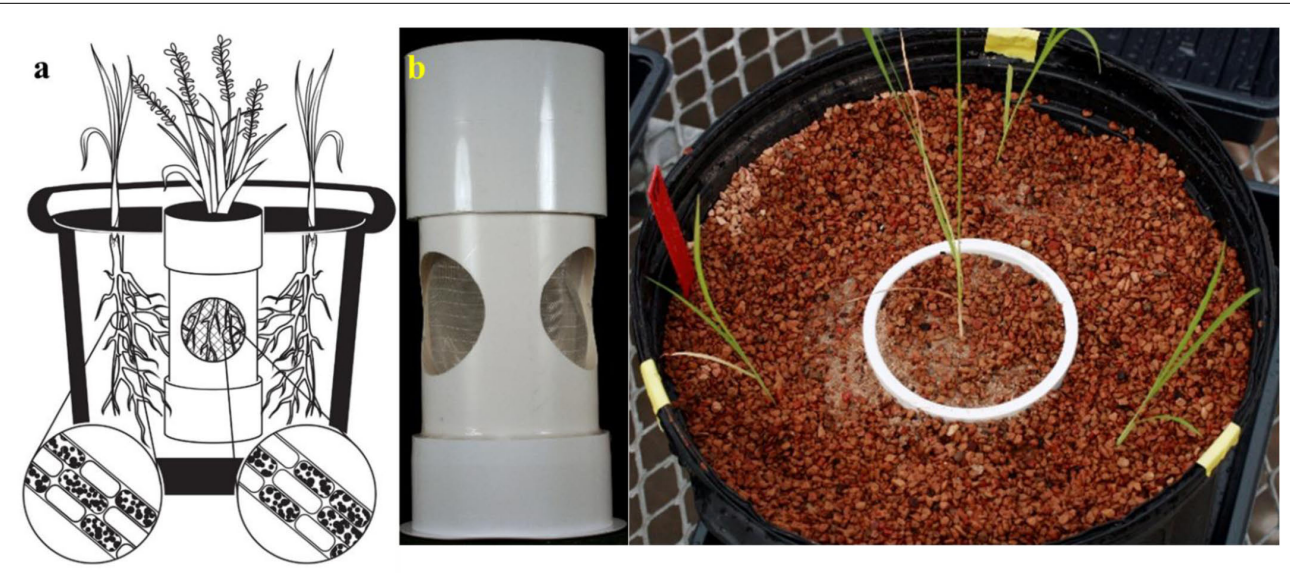

c

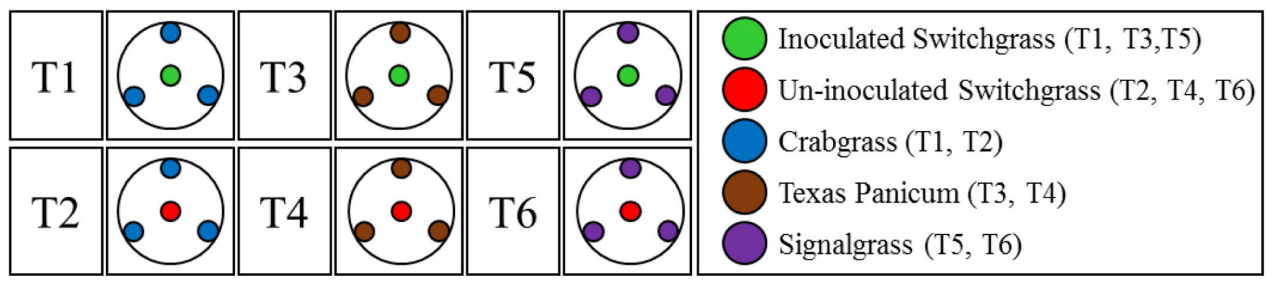

FIGURE 2 | The endocosm assembly to investigate the movement of S. vermifera between switchgrass and competing weeds mediated by vegetative mycelia. (a) An illustration of the endocosm assembly. The colonization of individual root cells at the end of the study by $S$. vermifera is represented by black dots (enlarged). (b) An actual endocosm experimental unit. Three circular openings were cut in a pipe. The openings were covered with fine nylon mesh to exclude the roots but allow the movement of fungal mycelia. The bottom of the pipe was sealed with a perforated base to allow water movement. This was placed in the center of 5 gallon pot. Switchgrass in the center was inoculated with S. vermifera. Three weeds planted in the periphery were un-inoculated. (c) The experimental design for the endocosm study. T1, T3, T5: Switchgrass in the center was inoculated with S. vermifera. T2, T4, T6: Switchgrass in the center was un-inoculated. T1, T2: Crabgrass in the periphery, T3, T4: Texas Panicum in the periphery, T5, T6: Signalgrass in the periphery.

named this assembly an "endocosm." The exocosm was designed to evaluate the ability of $S$. vermifera to colonize co-occurring weeds in a root free environment, and the endocosm assembly was designed to evaluate the ability of $S$. vermifera to colonize co-occurring weeds via co-mingled switchgrass and weed root systems.

For construction of the exocosm, five D25L single-cell root trainers $(7 \mathrm{~cm} \times 25 \mathrm{~cm} \mid$ diameter $\times$ height, Stuewe \& Sons, 
Inc., Tangent, OR United States) were used and interconnected by short PVC pipes $(2 \mathrm{~cm} \times 16 \mathrm{~cm} \mid$ diameter $\times$ length) (Figure 1b). The openings of the four connector pipes were covered with fine nylon mesh from either side to exclude roots but allow the movement of the finer fungal mycelia (Figure 1a). Both cones and the connectors were filled with Metro-Mix ${ }^{\circledR} 360$ potting mixture.

For the endocosm assembly, three circular openings $(6 \mathrm{~cm}$ diameter) were created in a pipe $(10 \mathrm{~cm} \times 23 \mathrm{~cm}$ | diameter $\times$ height) as shown in Figure $\mathbf{2 b}$. The openings were covered with fine nylon mesh (Figure 2a) to exclude the roots but allow the movement of fungal mycelia. The bottom of the pipe was sealed with a perforated base for water passage. This assembly was placed in the center of a 5 gallon pot and filled with Turface ${ }^{\circledR}$ MVP $^{\circledR}$ (Buffalo Grove, IL, United States).

\section{Experimental Set Up}

In the exocosm assembly (Figure 1b), a switchgrass seedling was transplanted in the central root trainer cell (C) and inoculated with $S$. vermifera using bentonite clay following the protocol developed in our laboratory (Ray et al., 2015). The four peripheral compartments $(1,2,3$, and 4$)$ of each exocosm were transplanted with un-inoculated weed seedlings of a single type. Separate exocosms were maintained for each of the three weed species. The experiment was conducted in triplicate and repeated twice in The Noble Research Institute's greenhouse facility.

The endocosm study was conducted using the assembly as described in Figure 2. A switchgrass seedling was transplanted in the central compartment and colonized with $S$. vermifera using bentonite clay. Three un-colonized weed seedlings were planted in the periphery, outside of the central compartment (Figures 2b,c). A similar setup with an un-inoculated switchgrass seedling in the center was also maintained as a control for each weed species. In all, the experimental design consisted of six treatments (Figure 2c), with four replicates per treatment. The experimental units were arranged in a randomized complete block design.

For both studies, the plants were maintained in the greenhouse for 8 weeks post transplanting, under standard conditions (temperature range, $26-29^{\circ} \mathrm{C}$ ) with $50 \%$ relative humidity under a 16:8 h photoperiod. Plants were watered $2 \sim 3$ times per week.

\section{Verification of the Colonization of Non-targeted Weeds by S. vermifera}

After 8 weeks, the colonization by $S$. vermifera was confirmed by nested PCR using S. vermifera (MAFF305830) specific primers (Ray et al., 2015). gDNA was isolated from inoculated and mock inoculated switchgrass and weed roots. The $3^{\prime}$ region of the $18 \mathrm{~S}$ (SSU), ITS1 and ITS2, the $5.8 \mathrm{~S}$ ribosomal subunit and the 25-28S (LSU) were amplified by direct PCR using NSSeb1 and NLSeb1.5R. Direct PCR amplified a $\sim 2.2 \mathrm{~kb}$ fragment. Subsequently, the primary PCR product was diluted to 1:200 and used as a template for a nested PCR using ITS3Seb and ITS3Seb-R primers covering the 5.8S-coding sequence and highly variable ITS2 region of $S$. vermifera ribosomal DNA (rDNA) (Figure 3).

Further, in the endocosm study where the two different rooting systems (switchgrass and weeds) were separate, but still in very close proximity (Figure 2a), the possibility of mixing between weed roots and switchgrass roots during harvesting was eliminated by running PCR on weed root DNA using switchgrass-specific primer PvCon1 (Supplementary Figure S1 and Supplementary Table S1).

\section{Effect of Non-targeted Colonization on the Biomass of Co-occurring Weeds}

In instances where the PCR screen revealed a co-occurring weed that was apparently infected by $S$. vermifera, the aboveground material was harvested for estimation of biomass to evaluate the effect of non-targeted colonization of $S$. vermifera on the biomass of co-occurring weeds.

\section{Data Analysis}

The data were analyzed using the Analysis of Variance (ANOVA) method. When a significant $F$-test was observed, treatment means were compared using least significant difference (LSD) at $p<0.05$ using CoStat statistical software 6.4 (Cohort Berkeley, CA, United States). The results were plotted graphically (Figure 4) using SigmaPlot 12.5 (Systat Software, San Jose, CA, United States).

\section{In Vitro Colonization of Host Plants by S. vermifera}

Colonization of switchgrass, signalgrass, and crabgrass roots by $S$. vermifera was initially confirmed by a PCR based assay (Figure 3B). Additionally, to obtain more direct evidence and to demonstrate that fungus does indeed penetrate the host root, we colonized switchgrass, signalgrass and crabgrass in vitro with S. vermifera.

Seeds of all three host plants were surface sterilized following the protocol modified after Xi et al. (2009) as described earlier. Sterilized seeds were placed onto large square petri dishes (120 mm, Greiner Bio-One North America Inc., Monroe, NC, United States) containing M media (Bécard and Fortin, 1988; Schultze, 2013), pH 5.5, and amended with 0.3\% Phytagel $^{\mathrm{TM}}$ (MilliporeSigma, St. Louis, MO, United States). Petri dishes were incubated in a Conviron ${ }^{\circledR}$ (Winnipeg, $\mathrm{MB}$, Canada) plant growth chamber for 7 days at $24^{\circ} \mathrm{C}$ with $60 \%$ relative humidity under 16:8 $\mathrm{h}$ photoperiod for seed germination.

For in vitro colonization, inoculum of $S$. vermifera was prepared by grinding $50 \mathrm{mg}$ (fresh wt. basis) of 2 weeks old vegetative mycelia in $500 \mu \mathrm{l}$ of $\mathrm{M}$ media. After seed germination, individual seedlings were inoculated by putting a drop $(10 \mu \mathrm{l})$ of inoculum with a sterile pipette on the media in close proximity $(\sim 3 \mathrm{~cm})$ to the roots. Inoculated seedlings were then incubated in the Conviron ${ }^{\circledR}$ plant growth chamber for two additional weeks. After 2 weeks in the Conviron ${ }^{\circledR}$, plants were harvested and the roots were subsequently processed for staining and microscopy.

\section{Fluorescence Staining and Confocal Microscopy}

S. vermifera-colonized root samples from switchgrass, signalgrass, and crabgrass were fixed in $50 \%(\mathrm{v} / \mathrm{v})$ ethanol for $1 \mathrm{~h}$ at room temperature immediately after harvesting 

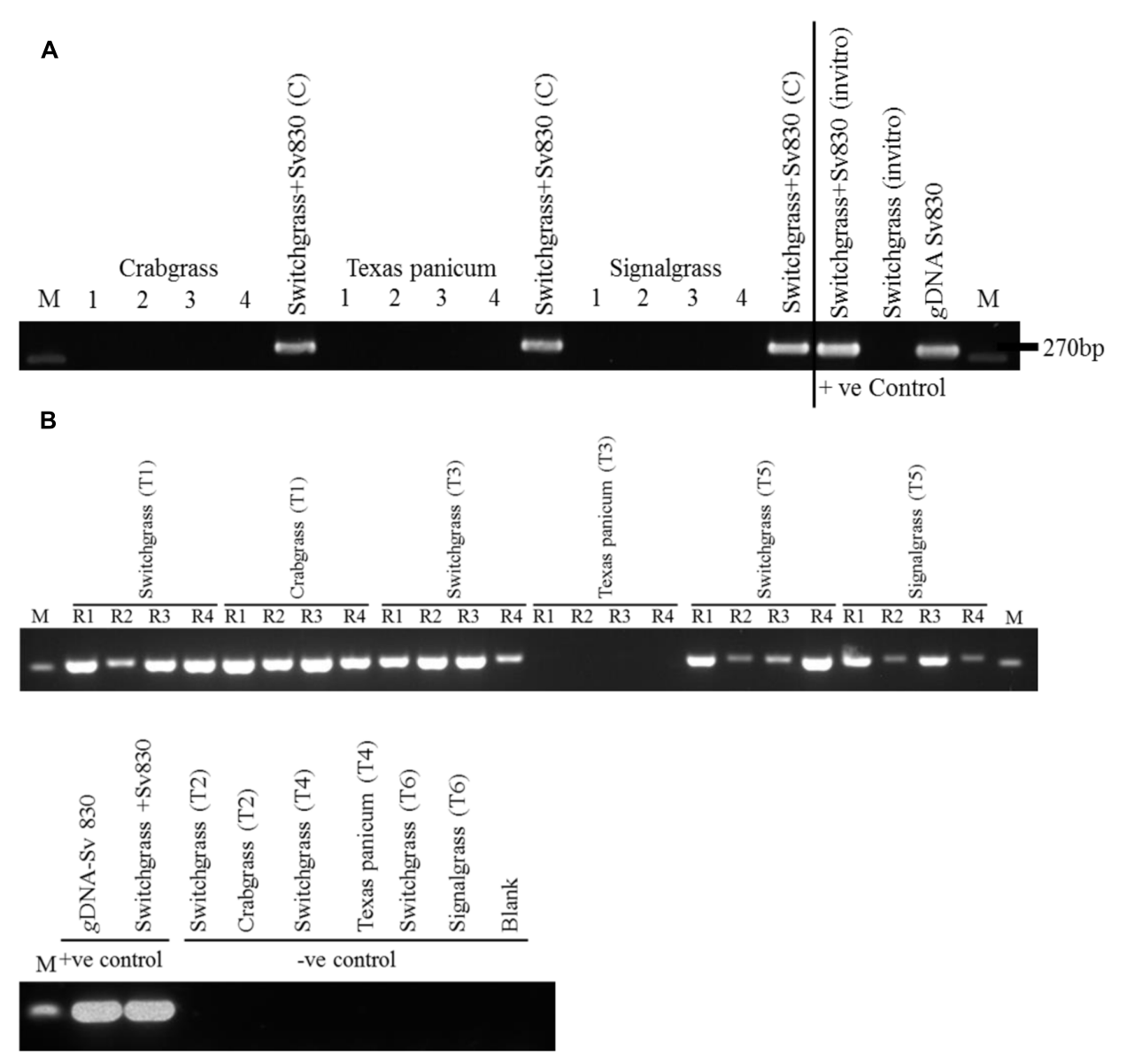

FIGURE 3 | (A) Verification of root colonization by S. vermifera in switchgrass and in the four peripheral weeds in the exocosm assembly. Sv830: S. vermifera (MAFF305830), M: Marker; 1 4: four peripheral un-inoculated weeds; Switchgrass+Sv830 (C): Inoculated switchgrass in the center. (B) Verification of root colonization by S. vermifera in switchgrass and in the peripheral weeds in the endocosm assembly. Sv830: S. vermifera (MAFF305830), M: Marker; R1 R4: Four replicate seedlings. T1, T3, T5: Switchgrass in the center was inoculated with S. vermifera. T2, T4, T6: Switchgrass in the center was un-inoculated. T1, T2: Crabgrass in the periphery, T3, T4: Texas Panicum in the periphery, T5, T6: Signalgrass in the periphery. Colonization was confirmed by nested PCR of switchgrass and weed root DNA by Serendipita specific primers. gDNA from S. vermifera pure culture, in vitro germinated switchgrass seedling colonized with or without S. vermifera respectively were used as controls for PCR assay.

(Bravo et al., 2016). Fixed root samples were then cleared with $20 \%(\mathrm{v} / \mathrm{v}) \mathrm{KOH}$ for $30 \mathrm{~min}$ at $50^{\circ} \mathrm{C}$. To visualize fungal vegetative mycelia, fixed and cleared roots were stained with $10 \mu \mathrm{g} / \mathrm{ml}$ aqueous solution of WGA-AF $488^{\circledR}$ (Life Technologies, Carlsbad, CA, United States) (Javot et al., 2007) overnight at room temperature. To visualize the plant cell wall, roots were then counter stained with $10 \mu \mathrm{g} / \mathrm{ml}$ aqueous solution of propidium iodide (PI: Biotium, Hayward, CA, United States) (De Smet et al., 2008; Pumplin et al., 2010) for $30 \mathrm{~min}$ at room temperature. Root samples were subsequently washed three times with distilled water in-between each chemical treatment. Root samples were finally cut into $1 \mathrm{~cm}$ long pieces and mounted onto glass slides using distilled water as the mounting media. Slides were transferred onto the stage of an inverted (inverted objective lenses) Leica TCS-SP8 point scanning confocal microscope (Leica Microsystems, Wetzlar, Germany) equipped with a 40x water-immersion objective lens. Fungal hyphae stained with WGA-AF $488^{\circledR}$ were excited using 488 -nm of the White Light
Laser (WLL), and emission was detected at 493-535 nm. Plant cell walls stained with PI were visualized by exciting at $538 \mathrm{~nm}$ by WLL, and emission was detected at 592-650 $\mathrm{nm}$. Sequential scanning between lines was used to detect WGA-AF 488 emission from fungal hyphae and PI from plant cell walls. Images were captured using the Leica TCS-SP8 running LAS X software (Leica Microsystems, Wetzlar, Germany), and images from these channels were overlaid to show fungal colonization in plant cells.

\section{RESULTS}

\section{Colonization of Switchgrass and Co-occurring Weeds by S. vermifera}

After 8 weeks, S. vermifera colonization in switchgrass and in the peripheral weeds were checked by nested PCR using S. vermifera specific primers (Supplementary Table S1). In the exocosm study, none of the three different types of weeds 

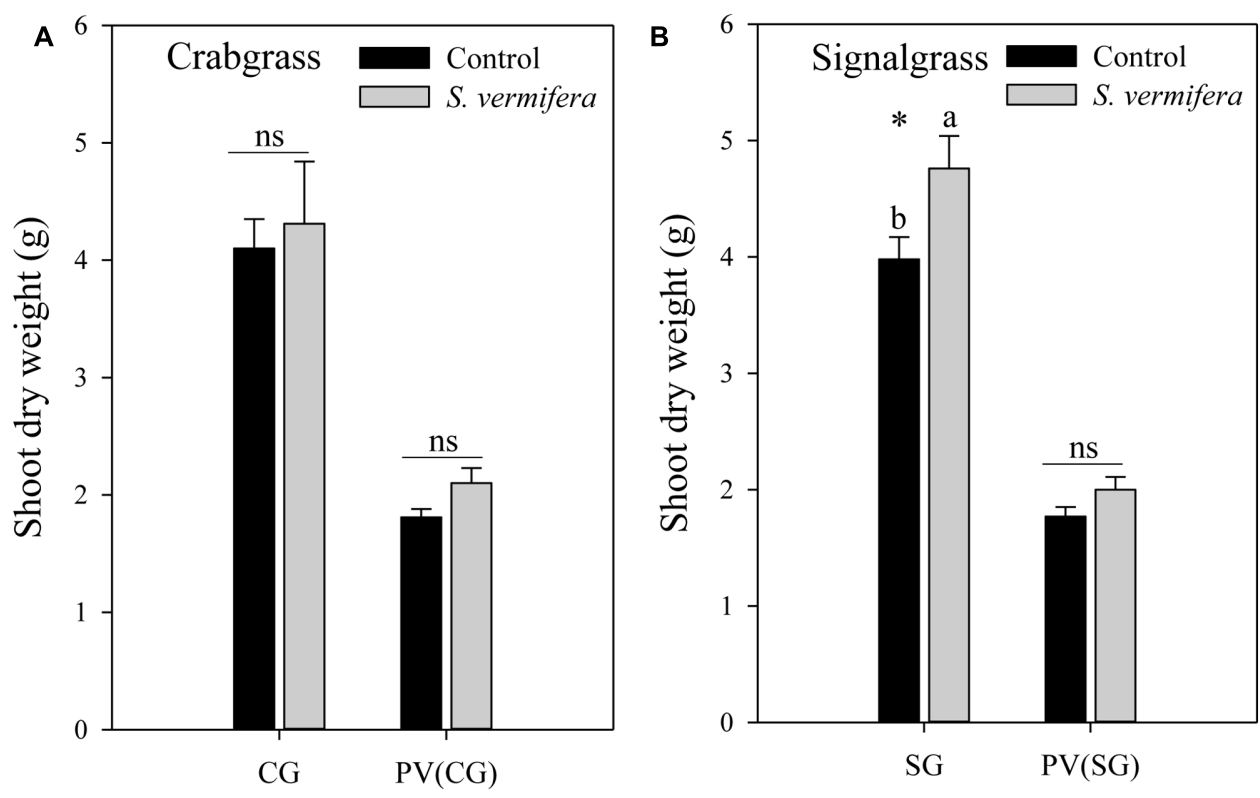

FIGURE 4 | Effect of non-targeted colonization of S. vermifera on biomass of (A) Crabgrass and (B) Signalgrass planted around central colonized or un-colonized control switchgrass in the endocosm assembly (Figure 2c) 8 weeks after colonization. Error bars denote standard error of mean. ns: $p$ > 0.05. CG: Crabgrass; SG: Signalgrass; PV(CG) and PV(SG): Switchgrass (Panicum virgatum) in the center surrounded by Crabgrass (CG) and Signalgrass (SG) respectively.

in the four peripheral cones were colonized by $S$. vermifera (Figure 3A). Further, we were unable to successfully amplify the S. vermifera-specific band from potting mix collected from the pipes connecting the cones, suggesting that either mycelia do not move freely through the inter-connected pipes or their relative abundance was beyond detectable limits by PCR. Conversely, in the endocosm study we found that crabgrass and signalgrass plants in the periphery were indeed colonized by $S$. vermifera when planted around a central, colonized switchgrass plant, while Texas Panicum remained un-infected (Figure 3B). Further, this "weed root DNA" was not contaminated by switchgrass root DNA, suggesting that very close proximity between the roots of the intended switchgrass host and those of nearby Crabgrass or Signalgrass weeds can result in unintended colonization of the latter.

\section{Non-targeted Colonization by S. vermifera Can Influence the Biomass of Weeds}

Having established that non-targeted colonization is possible, we evaluated whether it lead to biomass gains. Indeed in the endocosm, a mild increase in biomass of both crabgrass (ns) and signalgrass $\left({ }^{*} p<0.05\right)$ was observed when planted around a central colonized switchgrass plant, in comparison to those planted around the un-inoculated control (Figure 4). Although crabgrass and signalgrass were colonized in a non-targeted manner through seemingly co-mingled root systems when planted around colonized switchgrass, (Figure 3B), such non-targeted colonization did not contribute to a significant increase in biomass of crabgrass (Figure 4A) with respect to un-inoculated cohorts $(p>0.05)$. However, increase in biomass was significant in the case of signalgrass (Figure 4B) $\left({ }^{*} p<0.05\right.$ ). No significant increase in biomass was observed in switchgrass planted in the center, surrounded either by crabgrass or by signalgrass respectively. To summarize, although there was a trend of enhanced biomass when $S$. vermifera was present, both for the switchgrass and co-occurring crabgrass and signalgrass weeds, the increase in biomass was significant in case of signalgrass only. Besides this, it was also evident that, the biomass of competing weeds for the same period were almost twice as much as switchgrass (Figures 4A,B).

\section{Visualization of S. vermifera Colonization by Confocal Microscopy}

Confocal microscopic images of root cells of switchgrass, signalgrass and crabgrass colonized by $S$. vermifera are presented in Figure 5. S. vermifera root colonization is typically marked by sparse growth between cells and occasional cells containing dense intracellular packing of fungal hyphae. Interestingly, the extent of intracellular colonization in the three different grass species was also visually distinct, suggesting that the degree of colonization by $S$. vermifera may vary with plant host species.

\section{DISCUSSION}

There is currently no evidence that fungi in the Serendipitaceae can traverse any significant distance in the soil matrix and colonize nearby root systems. However, strains of this fungus (including the one tested herein) do form associations with hosts that initiates with plant recruitment of the fungus from the 

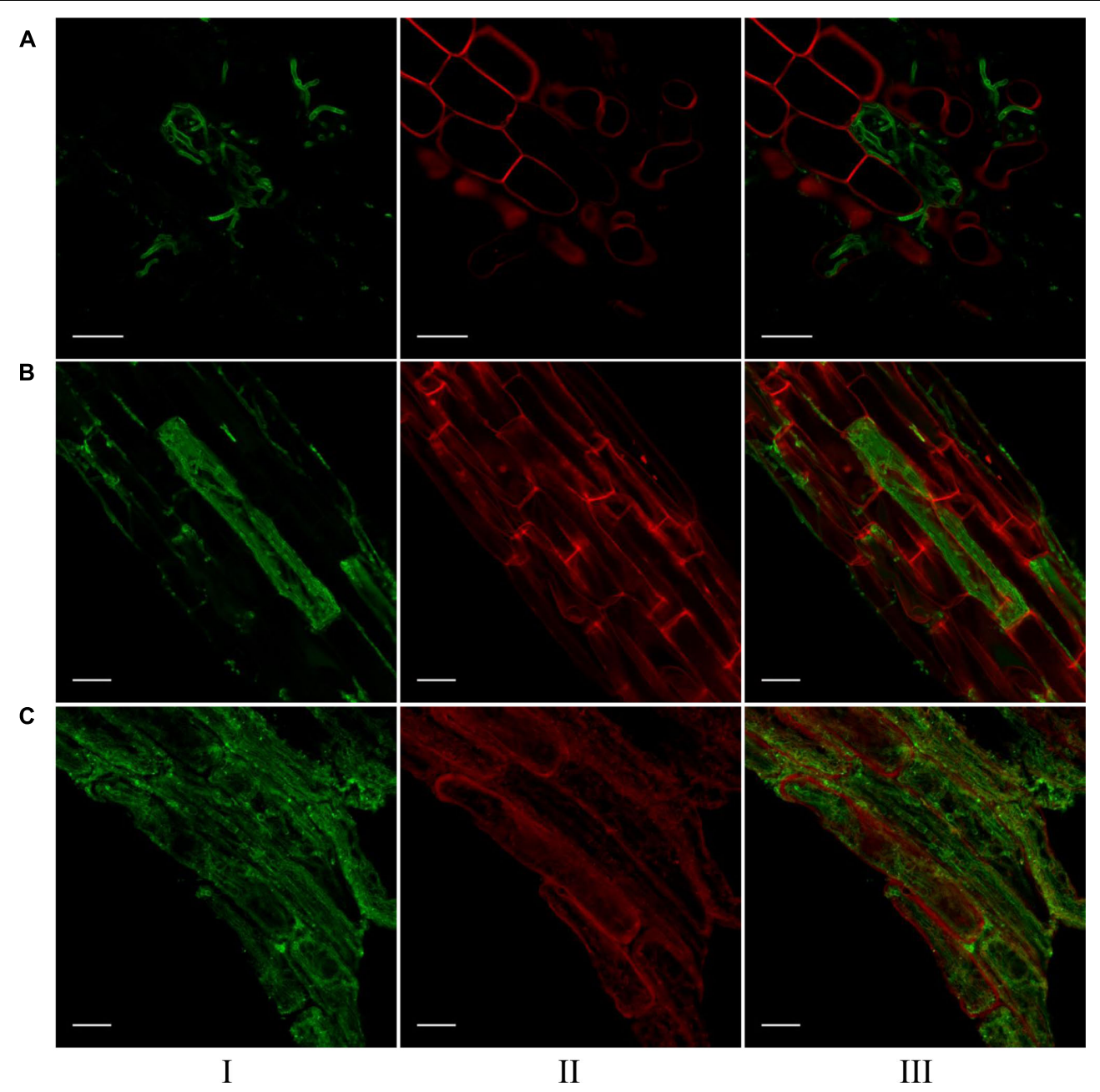

FIGURE $\mathbf{5}$ | Visualization of S. vermifera colonized root cells of (A) switchgrass, (B) signalgrass, and (C) crabgrass by confocal microscopy. Fungal hyphae stained with WGA-AF $488^{\circledR}$ were visualized in green channel (I). Plant cell wall stained with PI were visualized in red channel (II). Images from these channels were overlaid (III) to show fungal colonization in plant cells. Bar $=20 \mu \mathrm{m}$.

surrounding soil, suggesting that such movement is possible. Further, the movement of fungal mycelia through the soil matrix does occur naturally for other fungi such as Phialocephala spp. (Sieber and Grünig, 2006). Garnica et al. (2013) have even suggested the possibility of co-localized host plants being linked in a common mycelial network. A similar hypothesis has been suggested by Ryberg et al. (2009), who determined that dominating ectomycorrhizal fungi, including members of the Serendipitaceae, were shared by Dryas octopetala and Salix reticulata in an alpine cliff ecosystem in Northern Sweden. As our ultimate objective is to deploy Serendipitoid fungi as plant growth-promoting agents in the field, we performed this study to clarify the ability of one such strain (S. vermifera MAFF305830) to move within the soil matrix, such as occurs in other fungal groups (Taylor and Bruns, 1997; Vincenot et al., 2008).

In the exocosm study, we report that none of the three different type of weeds planted in the peripheral compartments were colonized by S. vermifera (Figure 3A). As the design of the exocosm restricts root growth to the central compartment, these findings suggest that mycelium of the Serendipitoid symbiont cannot traverse roughly $16 \mathrm{~cm}$ of soil in 8 weeks. Conversely, in the endocosm study, we found that crabgrass and signalgrass in the periphery were colonized by $S$. vermifera when planted surrounding the central pre-colonized switchgrass (Figure 3B). In contrast to the exocosm, the endocosm allows both switchgrass and the weed root systems to share the same space, separated only by a fine nylon membrane (Figure 2a). Thus, it would seem that one reason for the inability of $S$. vermifera to colonize peripheral weeds in the exocosm could be the rate of mycelial extension over time. However, since PCR with soil DNA in the connector region was also negative, we cannot substantiate this hypothesis. In a separate field study where wheat plants inoculated with this fungus are grown in a plot alongside un-inoculated plants at one foot $(30.48 \mathrm{~cm})$ intervals, we also fail to find "new colonization events" where an initially fungus-free plant becomes colonized 
over the growing season ( $\sim 8$ months) (data not presented). From these data, it would seem that migration of this strain of S. vermifera is fairly limited, even in an initially sterile growth medium where, presumably, competition is not a factor.

Incidence of non-targeted colonization by $S$. vermifera significantly improve biomass of signalgrass but not crabgrass in our study. However, we failed to observe the typical significant $(p<0.05)$ biomass gains we would expect in switchgrass (Ghimire and Craven, 2011; Ray et al., 2015), likely due to the low number of replicates (three) included in this study. Besides this, the biomass of competing weeds for the same period were almost twice as much as switchgrass (Figure 4). This could be another reason behind non-significant biomass increase in switchgrass when Serendipita was present. Our objective essentially focused on migration of the symbiont, but to address the question of whether this fungus can significantly improve biomass of these weedy species would require additional study.

As those of us in the scientific community working with these Serendipitaceae fungi have thus far been unable to identify a non-host, assessing the impact of introducing this symbiont to any native rhizosphere is highly relevant. Herein we provide evidence that $S$. vermifera can indeed migrate through the interconnected network of roots of co-occurring plant species resulting in un-intended colonization of non-targeted plants. However, such migration is very limited, and we hypothesize that new infections would likely be rare events.

Further, unlike crabgrass and signalgrass, Texas panicum was not colonized by $S$. vermifera. This suggests the possibility that this plant is not an effective host for this strain of S. vermifera, a hypothesis we are currently following up on.

The undesired colonization of non-target crops by any plant growth promoting microbe is likely a real phenomenon that merits serious cause for caution and study. It is our opinion that the utilization of native strain(s) of such microbes, including S. vermifera, is the approach with perhaps the fewest negative consequences. Further, native strains are presumable adapted to the particular agro-climatic region they are intended for, thus enhancing their potential for persistence and effectiveness, while ameliorating issues related to weed management and regulation. Our laboratory has recently isolated the first North American strain of Serendipita, named Serendipita vermifera ssp. bescii, from the roots of a switchgrass plant (Ray and Craven, US patent pending). Using native microorganisms should diminish

\section{REFERENCES}

Bécard, G., and Fortin, J. (1988). Early events of vesicular-arbuscular mycorrhiza formation on Ri T-DNA transformed roots. New Phytol. 108, 211-218. doi: 10.1111/j.1469-8137.1988.tb03698.x

Blount, A. R., Ball, D. M., Sprenkel, R. K., Myer, R. O., and Hewitt, T. D. (2003). Crabgrass as a Forage and Hay Crop. Gainesville, FL: University of Florida.

Bravo, A., York, T., Pumplin, N., Mueller, L. A., and Harrison, M. J. (2016). Genes conserved for arbuscular mycorrhizal symbiosis identified through phylogenomics. Nat. Plants 2:15208. doi: 10.1038/nplants.2015.208

DeMars, B., and Boerner, R. (1996). Vesicular arbuscular mycorrhizal development in the Brassicaceae in relation to plant life span. Flora 191, 179-189. doi: 10.1016/S0367-2530(17)30711-9 the potential for invasiveness or other adverse non-target effects on the native soil microbiota. Hence, $S$. bescii could be of special interest for application to the fields of the Southern Great Plains of United States in the future.

\section{AUTHOR CONTRIBUTIONS}

PR and YG carried out all the experiments. JK conducted the confocal microscopy. PR and KC planned the experiments, analyzed the data and wrote the article.

\section{FUNDING}

This work was supported by the United States Department of Energy, Bioenergy Research Center, through the Office of Biological and Environmental Research in the DOE Office of Science.

\section{ACKNOWLEDGMENTS}

Serendipita vermifera (MAFF-305830) used in this study was obtained from the National Institute of Agro-biological Sciences, Tsukuba, Ibaraki, Japan. Seeds of large crabgrass (Digitaria sanguinalis), Texas panicum (Panicum texanum), and broadleaf signalgrass (Brachiaria platyphylla) were procured from Dr. Twain Butler's laboratory at The Noble Research Institute, LLC. The authors thank Jongjin Park for providing switchgrass specific primers, Jin Nakashima for technical assistance with confocal microscopy, Amanda Hammon for greenhouse assistance, Charles Bench and Tony Ballard for preparing microcosm assembly, Rachael Davis for line drawings and Venkatachalam Lakshmanan for critical review of the manuscript.

\section{SUPPLEMENTARY MATERIAL}

The Supplementary Material for this article can be found online at: https://www.frontiersin.org/articles/10.3389/fpls.2017.02236/ full\#supplementary-material

De Smet, I., Vassileva, V., De Rybel, B., Levesque, M. P., Grunewald, W., Van Damme, D., et al. (2008). Receptor-like kinase ACR4 restricts formative cell divisions in the Arabidopsis root. Science 322, 594-597. doi: 10.1126/science. 1160158

Garnica, S., Riess, K., Bauer, R., Oberwinkler, F., and Weiß, M. (2013). Phylogenetic diversity and structure of sebacinoid fungi associated with plant communities along an altitudinal gradient. FEMS Microbiol. Ecol. 83, 265-278. doi: 10.1111/ j.1574-6941.2012.01473.x

Ghimire, S. R., and Craven, K. D. (2011). Enhancement of switchgrass (Panicum virgatum L.) biomass production under drought conditions by the ectomycorrhizal fungus Sebacina vermifera. Appl. Environ. Microbiol. 77, 7063-7067. doi: 10.1128/AEM.05225-11

Javot, H., Penmetsa, R. V., Terzaghi, N., Cook, D. R., and Harrison, M. J. (2007). A Medicago truncatula phosphate transporter indispensable for the 
arbuscular mycorrhizal symbiosis. Proc. Natl. Acad. Sci. U.S.A. 104, 1720-1725. doi: 10.1073/pnas.0608136104

Kering, M. K., Huo, C., Interrante, S. M., Hancock, D. W., and Butler, T. J. (2013). Effect of various herbicides on warm-season grass weeds and switchgrass establishment. Crop Sci. 53, 666-673. doi: 10.2135/cropsci2012.04. 0252

Ma, Z., Wood, C. W., and Bransby, D. I. (2000). Soil management impacts on soil carbon sequestration by switchgrass. Biomass Bioenergy 18, 469-477. doi: 10.1016/S0961-9534(00)00013-1

Marx, D. H. (1969). The influence of ectotrophic mycorrhizal fungi on the resistance of pine roots to pathogenic infections I antagonism of mycorrhizal fungi to root pathogenic fungi and soil bacteria. Phytopathology 59, 153-163.

McLaughlin, S. B., and Kszos, L. A. (2005). Development of switchgrass (Panicum virgatum) as a bioenergy feedstock in the United States. Biomass Bioenergy 28, 515-535. doi: 10.1016/j.biombioe.2004.05.006

Miller, J. F., Worsham, A. D., McCormick, L. L., Davis, D. E., Coefer, R., and Smith, J. A. (1975). Weeds of Southern United States. Raleigh, NC: The North Carolina Agricultural Extension Service.

Mitchell, R., Vogel, K. P., and Sarath, G. (2008). Managing and enhancing switchgrass as a bioenergy feedstock. Biofuels Bioprod. Bioref. 2, 530-539. doi: $10.1002 / b b b .106$

Oberwinkler, F., Riess, K., Bauer, R., Selosse, M.-A., Weiß, M., Garnica, S., et al. (2013). Enigmatic sebacinales. Mycol. Prog. 12, 1-27. doi: 10.1007/s11557-0120880-4

O’Donnell, K. (1993). "Fusarium and its near relatives," in The Fungal Holomorph: Mitotic, Meiotic and Pleomorphic Speciation in Fungal Systematics, eds D. R. Reynolds and J. W. Taylor (Wallingford: CAB International), 225-233.

Pumplin, N., Mondo, S. J., Topp, S., Starker, C. G., Gantt, J. S., and Harrison, M. J. (2010). Medicago truncatula Vapyrin is a novel protein required for arbuscular mycorrhizal symbiosis. Plant J. 61, 482-494. doi: 10.1111/j.1365-313X.2009. 04072.x

Ray, P., and Craven, K. D. (2016). Sebacina vermifera: a unique root symbiont with vast agronomic potential. World J. Microbiol. Biotechnol. 32, 1-10. doi: 10.1007/s11274-015-1970-7

Ray, P., Ishiga, T., Decker, S. R., Turner, G. B., and Craven, K. D. (2015). A Novel delivery system for the root symbiotic fungus, Sebacina vermifera, and consequent biomass enhancement of low lignin COMT switchgrass lines. BioEnergy Res. 8, 922-933. doi: 10.1007/s12155-015-9636-8

Renz, M., Undersander, D., and Casler, M. (2009). Establishing and Managing Switchgrass. Madison, WI: UW Extension.

Ryberg, M., Larsson, E., and Molau, U. (2009). Ectomycorrhizal diversity on Dryas octopetala and Salix reticulata in an alpine cliff ecosystem. Arct. Antarct. Alp. Res. 41, 506-514. doi: 10.1657/1938-4246-41.4.506
Schmer, M. R., Vogel, K. P., Mitchell, R. B., Moser, L. E., Eskridge, K. M., and Perrin, R. K. (2006). Establishment stand thresholds for switchgrass grown as a bioenergy crop. Crop Sci. 46, 157-161. doi: 10.2135/cropsci2005. 0264

Schultze, M. (2013). Protocols for growing plant symbioses; mycorrhiza. Methods Mol. Biol. 953, 47-59. doi: 10.1007/978-1-62703-152-3_3

Selosse, M. A., Bauer, R., and Moyersoen, B. (2002). Basal hymenomycetes belonging to the Sebacinaceae are ectomycorrhizal on temperate deciduous trees. New Phytol. 155, 183-195. doi: 10.1046/j.1469-8137.2002.00442.x

Sieber, T. N., and Grünig, C. R. (2006). "Biodiversity of fungal root-endophyte communities and populations particular of the dark septate endophyte Phialocephala fortinii s. l," in Microbial Root Endophytes Soil Biology Series, eds B. Schulz, C. Boyle, and T. N. Sieber (Berlin: Springer), 107-132. doi: 10.1007/3-540-33526-9_7

Suarez, J. P., Weiss, M., Abele, A., Oberwinkler, F., and Kottke, I. (2008). Members of Sebacinales subgroup B form mycorrhizae with epiphytic orchids in a neotropical mountain rain forest. Mycol. Prog. 7, 75-85. doi: 10.1007/s11557008-0554-4

Taylor, D. L., and Bruns, T. D. (1997). Independent, specialized invasions of ectomycorrhizal mutualism by two nonphotosynthetic orchids. Proc. Natl. Acad. Sci. U.S.A. 94, 4510-4515. doi: 10.1073/pnas.94.9.4510

Vincenot, L., Tedersoo, L., Richard, F., Horcine, H., Koljalg, U., and Selosse, M. A. (2008). Fungal associates of Pyrola rotundifolia, a mixotrophic Ericaceae, from two Estonian boreal forests. Mycorrhiza 19, 15-25. doi: 10.1007/s00572-0080199-9

Warcup, J. H. (1988). Mycorrhizal associations of isolates of Sebacina vermifera. New Phytol. 110, 227-231. doi: 10.1111/j.1469-8137.1988.tb00256.x

Weiss, M., Sykorova, Z., Garnica, S., Riess, K., Martos, F., Krause, C., et al. (2011). Sebacinales everywhere: previously overlooked ubiquitous fungal endophytes. PLOS ONE 6:e16793. doi: 10.1371/journal.pone.0016793

Xi, Y., Fu, C., Ge, Y., Nandakumar, R., Hisano, H., Bouton, J., et al. (2009). Agrobacterium-mediated transformation of switchgrass and inheritance of the transgenes. BioEnergy Res. 2, 275-283. doi: 10.1007/s12155-009-9049-7

Conflict of Interest Statement: The authors declare that the research was conducted in the absence of any commercial or financial relationships that could be construed as a potential conflict of interest.

Copyright (c) 2018 Ray, Guo, Kolape and Craven. This is an open-access article distributed under the terms of the Creative Commons Attribution License (CC BY). The use, distribution or reproduction in other forums is permitted, provided the original author(s) or licensor are credited and that the original publication in this journal is cited, in accordance with accepted academic practice. No use, distribution or reproduction is permitted which does not comply with these terms. 